\title{
EVALUASI PERENCANAAN DAN PENGADAAN OBAT DI INSTALASI FARMASI RUMAH SAKIT MITRA SIAGA KABUPATEN TEGAL
}

\author{
Tiara Fany Safitri ${ }^{* 1}$, Yulian Wahyu Permadi², St. Rahmatullah ${ }^{3}$ \\ ${ }^{*}, 2,3$ Program Studi Farmasi, Fakultas Ilmu Kesehatan, Universitas Muhammadiyah Pekajangan Pekalongan \\ e-mail: ${ }^{* 1}$ trfnysftr@gmail.com, ${ }^{2}$ y.wahyu.permadi@umpp.ac.id, ${ }^{3}$ amma88.an@gmail.com
}

\begin{abstract}
ABSTRAK
Manajemen pengelolaa obat sangatlah berperan penting dalam meningkatkan pelayanan kefarmasian di Instalasi farmasi rumah sakit dan salah satu aspek untuk menentukan suksesnya program pengobatan secara rasional di Rumah Sakit. Penelitian ini bertujuan untuk mengetahui pelaksanaan standar pelayanan pengelolaan sediaan farmasi terkair proses perencanaan dan pengadaan obat yang sesuai dengan Petunjuk Teknis Standar Pelayanan Kefarmasian Di Rumah Sakit 2019. Metode yang digunakan dalam penelitian ini bersifat deskriptif dengan menggunakan teknik total sampling sebanyak 11 responden dengan pengambilan data menggunakan kuisioner dan wawancara dengan kepala IFRS. Hasil evaluasi dari penelitian ini bahwa perencanaan kebutuhan sesuai (100\%) dan proses pengadaan obat (90,5\%) sesuai Petunjuk Teknis Standar Pelayanan Kefarmasian di Rumah Sakit 2019
\end{abstract}

Kata kunci: Evaluasi, Perencanaan, Pengadaan.

\begin{abstract}
Drug management plays an important role in improving pharmaceutical services in hospital pharmacy installations and one of the aspects to determine the success of rational treatment programs in hospitals. This study aims to determine the implementation of standard pharmaceutical preparations management services related to the planning and procurement process of drugs in accordance with the Technical Guidelines for Pharmaceutical Services Standards in Hospitals 2019. The method used in this study is descriptive by using a total sampling technique of 11 respondents with data collection using questionnaire and interview with the head of IFRS. The results of the evaluation of this study indicate that the planning needs are appropriate (100\%) and the drug procurement process $(90.5 \%)$ is in accordance with the Technical Guidelines for Pharmaceutical Services Standards in Hospitals 2019
\end{abstract}

Keywords: Evaluation, Planning, Procurement

\section{PENDAHULUAN}

Rumah sakit adalah institusi pelayanan kesehatan yang menyelenggarakan pelayanan kesehatan seseorang secara paripurna yang menyediakan pelayanan rawat inap, rawat jalan dan gawat darurat. Upaya kesehatan bermanfaat memelihara dan meningkatkan kesehatan serta tempat yang dipakai untuk kegiatan disebut sebagai sarana kesehatan. Sarana kesehatan berfungsi buat melakukan upaya kesehatan dasar atau upaya penunjang kesehatan. Selain itu, sarana kesehatan bisa juga digunakan buat kepentingan pendidikan, training dan penelitian pengembangan ilmu pengetahuan teknologi dibidang kesehatan. Salah satu sarana kesehatan yang menyelenggarakan upaya kesehatan rumah sakit. Tugas dan fungsi Rumah Sakit meliputi kegiatan, diantaranya yaitu memberi pelayanan medis, pelayanan penunjang medis, memberi pelayanan kedokteran kehakiman, pelayanan medis khusus, memberi pelayanan rujukan kesehatan, pelayanan kedokteran gigi, memberikan pelayanan sosial, pelayanan kesehatan, memberikan pelayanan rawat inap dan rawat jalan serta memberikan pelayanan rawat darurat dan rawat intensif, kemudian memberikan pendidikan medis secara umum serta khusus, memberikan fasilitas penelitian dan pengembangan ilmu kesehatan, memberikan kegiatan penyelidikan epidemiologi. Rumah sakit perlu mengembangkan kebijakan pengelolaan obat untuk meningkatkan keamanan, khususnya obat yang perlu diwaspadai (High-alert medication). High alert medication merupakan obat yang wajib 
diwaspadai karena sering menyebabkan terjadinya kesalahan ataupun kesalahan serius (sentinel event) dan obat yang berisiko tinggi menyebabkan reaksi obat yang tidak diinginkan atau biasa disingkat ROTD [1].

Instalasi Farmasi harus memiliki Apoteker dan tenaga teknis kefarmasian yang mana sesuai dengan beban kerja serta petugas penunjang lain agar dapat tercapai sasaran serta tujuan Instalasi Farmasi. Ketersediaan jumlah tenaga Apoteker dan Tenaga Teknis Kefarmasian di Rumah Sakit dipenuhi sesuai dengan ketentuan klasifikasi dan perizinan Rumah Sakit yang telah ditetapkan oleh Menteri. Apoteker bertanggung jawab terhadap pengelolaan Sediaan Farmasi, Alat Kesehatan dan Bahan Medis Habis Pakai di Rumah Sakit yang mana menjamin semua rangkaian kegiatan perbekalan Sediaan Farmasi, Alat Kesehatan dan Bahan Medis Habis Pakai sesuai dengan ketentuan yang berlaku serta memastikan kualitas, manfaat dan keamanannya. Pengelolaan Sediaan Farmasi, Alat Kesehatan dan Bahan Medis Habis Pakai adalah suatu alur kegiatan yang dimulai dari pemilihan, perencanaan kebutuhan, pengadaan, penerimaan, penyimpanan, pendistribusian, pemusnahan dan penarikan, pengendalian dan administrasi yang dibutuhkan bagi kegiatan Pelayanan Kefarmasian [1].

Menurut Permenkes RI Tahun 2016 [1], Perencanaan kebutuhan adalah kegiatan yang bertujuan untuk menentukan jumlah dan periode pengadaan Sediaan Farmasi, Alat Kesehatan dan Bahan Medis Habis Pakai sesuai dengan hasil kegiatan pemilihan untuk menjamin terpenuhinya kriteria khusunya tepat jenis, tepat jumlah, tepat waktu dan efisien. Perencanaan dilakukan untuk menghindari kekosongan obat dengan menggunakan metode yang dapat dipertanggungjawabkan serta dasar-dasar perencanaan yang sudah ditentukan diantaranya konsumsi, epidemiologi yang disesuaikan dengan anggaran yang tersedia. Pedoman perencanaan harus mempertimbangkan hal berikut, seperti anggaran yang telah tersedia, penetapan pada prioritas, sisa pada persediaan, data pemakaian pada periode yang lalu, waktu tunggu saat pemesanan, dan rencana pada pengembangan.

Pengadaan adalah kegiatan yang bertujuan untuk merealisasikan perencanaan kebutuhan. Pengadaan yang efektif harus menjamin ketersediaan, jumlah dan waktu yang tepat dengan harga yang terjangkau serta sesuai standar mutu. Pengadaan yaitu kegiatan yang mana berkesinambungan dimulai dari pemilihan, penentuan jumlah yang dibutuhkan, penyesuaian antara kebutuhan dan dana, pemilihan metode pengadaan, pemilihan pemasok, penentuan spesifikasi kontrak, pemantauan proses pengadaan dan pembayaran. Untuk memastikan Sediaan Farmasi, Alat Kesehatan, Bahan Medis Habis Pakai sesuai dengan mutu dan spesifikasi yang sesuai dengan ketentuan maka apabila proses pengadaan dilaksanakan oleh bagian lain di luar Instalasi Farmasi harus melibatkan tenaga kefarmasian. Beberapa hal yang perlu diperhatikan dalam pengadaan Sediaan Farmasi, Alat Kesehatan dan Bahan Medis Habis Pakai antara lain : Bahan baku obat harus selalu disertai sertifikat analisa, Bahan berbahaya harus selalu menyertakan Material Safety Data Sheet (MSDS), Sediaan Farmasi, Alat Kesehatan dan Bahan Medis Habis Pakai harus memiliki Nomor Izin Edar, Masa kadaluarsa (Expired date) minimal 2 (dua) tahun kecuali untuk Sediaan Farmasi, Alat Kesehatan dan Bahan Medis Habis Pakai tertentu (vaksin, reagensia dan lain-lain), atau pada saat kondisi tertentu yang dapat dipertanggung jawabkan

Pelayanan kesehatan di rumah sakit berdekatan dengan penggunaan perbekalan farmasi yang terdiri dari obat-obatan, bahan kimia, bahan radiologi, alat kesehatan habis pakai, alat-alat kedokteran dan gas medik. Selain itu pemasukkan rumah sakit yang berasal dari pengelolaan perbekalan farmasi adalah sekitar 50\% dari seluruh pemasukkan rumah sakit. Adapun standar pelayanan kefarmasian yang ada di instalasi farmasi rumah sakit adalah pengelolaan sediaan farmasi, alat kesehatan, BMHP dan pelayanan farmasi klinik. Apoteker harus berperan serta dalam pelayanan kefarmasian dan bertemu langsung dengan pasien untuk mendapatkan terapi pasien secara optimal [2]. 
Kegiatan Pelayanan kefarmasian di Rumah Sakit antara lain; kegiatan yang bersifat manajerial berupa pengelolaan Sediaan Farrmasi, Alat kesehatan dan Bahan Medis Habis Pakai, kemudian kegiatan pelayanan farmasi klinik [1]. Pada kegiatan pelayanan kefarmasian ini pelayanan yang dilakukan langsung dan bertanggung jawab kepada pasien yang berkaitan dengan sediaan farmasi dengan maksud mencapai hasil yang pasti untuk meningkatkan mutu kehidupan pasien. Peningkatan mutu pelayanan kefarmasian diharuskan merubah pelayanan dengan awalnya hanya berorientasi kepada produk (drug oriented) menjadi pelayanan baru yang berorientasi pada pasien (patient oriented) [3].

Menurut penelitian Gregorius [4] perencanaan dan pengadaan obat yang dilakukan di RSUD Kefamenanu belum berjalan sesuai dengan prosedurya, dapat dilihat dari perhitungan jumlah pengadaan dan waktu pengadaan yang masih berdasarkan perkiraan saja serta masih terdapat kekosongan dari beberapa persediaan obat yang mana pemilihan obat di RSUD Kefamennanu ini mengacu pada formularium nasional tetapi masih terdapat obat yang direncanakan di luar formularium nasional. Seleksi obat, perencanaan kebutuhan obat, perhitungan kebutuhan obat sudah berjalan namun masih belum sesuai dengan Standard Nasional serta sumber anggaran berdasarkan Dana Otsus dan APBD Rumah Sakit Umum Kabupaten Raja Ampat belum terlaksana secara maksimal [5].

Menurut Meity [6] tentang Analisis Pengelolaan Obat Di Instalasi Rawat Inap Rumah Sakit Jantung Bina Waluya Jakarta Timur Tahun 2019 menyatakan bahwa pengelolaan obat masih belum efektif, hal ini disebabkan masih ada beberapa komponen yang belum memenuhi persyaratan yaitu sarana dan prasarana serta proses penyimpanan yang tidak sesuai dengan Peraturan Menteri Kesehatan Republik Indonesia Nomor 72 Tahun 2016 tentang pelayanan kefarmasian di rumah sakit. Dampak yang muncul dari tidak berjalannya suatu proses manajemen pengelolaan obat akan mempengaruhi kesiapan obat di rumah sakit. Dampak buruk dari tidak siapnya obat juga sangat mempengaruhi penyembuhan pasien dan juga melemahkan mutu terhadap rumah sakit itu sendiri. Oleh karena itu rumah sakit harus sesuai berdasarkan aturan-aturan tentang pengelolaan obat. Selain itu rumah sakit juga wajib mempunyai SOP untuk petunjuk dalam menjalankan pengelolaan sediaan farmasi yang dilakukan oleh instalasi farmasi rumah sakit.

Manajemen pengelolaan obat merupakan salah satu bagian yang memiliki peranan penting dalam berlangsungnya pengelolaan obat yang ada di rumah sakit dan apabila salah satu dari proses pengelolaan obat tidak berjalan baik atau mengalami kendala. Maka dampaknya akan menghalangi atau mempengaruhi sistem pengelolaan obat seperti mengalami kehabisan stok obat dan menurunkan mutu kualitas pada Instalasi Farmasi itu sendiri [1].

Rumah Sakit Mitra Siaga adalah rumah sakit umum (RSU) milik Swasta dan merupakan salah satu rumah sakit tipe $\mathrm{C}$ yang terletak di wilayah Tegal, Jawa Tengah. Rumah sakit ini memberikan pelayanan di bidang kesehatan yang didukung oleh layanan dokter spesialis serta ditunjang dengan fasilitas medis lainnya.

Oleh karena itu hal yang ingin didapat dari penelitian ini adalah untuk mengetahui bagaimana proses perencanaan dan pengadaan obat di Instalasi Farmasi Rumah Mitra Siaga Kabupaten Tegal berdasarkan dengan berdasarkan Petunjuk Teknis Standar Pelayanan Kefarmasian di Rumah Sakit 2019. 


\section{METODE PENELITIAN}

\subsection{Instrumen Penelitian}

Lembar kuisioner, panduan wawancara, bolpoint, alat perekam (HP) dan buku Petunjuk Teknis Standar Pelayanan Kefarmasian Di Rumah Sakit 2019

Jenis metode yang digunakan pada penelitian ini bersifat deskriptif kualitatif dengan penilaian kuisioner menggunakan skala guttman dimana penelitan mendapatkan jawaban tegas yaitu IYA atau TIDAK

\begin{tabular}{cll} 
No & \multicolumn{1}{c}{ Rentang } & \multicolumn{1}{c}{ Kategori } \\
1 & $0-20 \%$ & Sangat Kurang \\
2 & $21-40 \%$ & Kurang \\
3 & $41-60 \%$ & Cukup \\
4 & $61-80 \%$ & Baik \\
5 & $81-100 \%$ & Sangat Baik
\end{tabular}

\subsection{Jalannya Penelitian}

Peneliti mendapatkan surat jalan untuk penelitian dari LPPM, melakukan perizinan ke BAPPEDA Kabupaten Tegal dan RS Mitra Siaga, setelah mendapatkan izin peneliti melakukan penelitian dengan menggunakan teknik total sampling dimana responden yang terpilih telah memenuhi kriteria inklusi yang meliputi minimal Diploma Farmasi, telah bekerja lebih dari satu tahun dan paham terkait pengelolaan obat yang ada di IFRS. Kemudian metode pengambilan data menggunakan wawancara dan kuisioner. Kepada kepala IFRS dilakukan wawancara dan TTK menggunakan kuisioner setelah itu peneliti melakukan olah data dengan menggunakan SPSS versi 23 dengan menghitung data frekuensi,

\subsection{Analisis Data}

Metode analisis data yang digunakan pada penelitian ini menggunakan analisis isi dan SPSS versi 23

\section{HASIL DAN PEMBAHASAN}

Penelitian ini dilakukan pada tanggal 5 sampai 9 April 2021 di Rumah sakit Mitra Siaga. Penelitian ini bertujuan untuk mengetahui bagaimana proses perencanaan kebutuhan dan pengadaan obat yang ada di Instalasi Farmasi Rumah Sakit Mitra Siaga. Pengambilan sampel dilakukan dengan menggunakan teknik total sampling dengan melihat kriteria inklusi yang meliputi minimal diploma farmasi, bekerja di Instalasi Farmasi Rumah Sakit dan sudah bekerja selama 1 tahun dan kemudian didapatkan responden sebanyak 11 responden yang terdiri dari 3 Apoteker dan 9 Tenaga Teknis Kefarmasian yang ada di IFRS. Adapun pengambilan data yang dilakukan oleh peneliti menggunakan kuisioner dan wawancara mendalam dengan kepala instalasi farmasi rumah sakit yang bertanggung jawab terhadap semua aktivitas yang berada di Instalasi farmasi Rumah Sakit. Analisis yang digunakan dalam penelitian ini menggunakan analisis univariat yaitu untuk menganalisis variabel-variabel secara deskriptif dengan cara menghitung frekuensi masing-masing variabel nantinya digunakan untuk menghitung persentase manajemen pengelolaan logistik obat yang meliputi proses pemilihan sampain administrasi yang terdapat dalam beberapa pertanyaan soal yang ada di kuisioner berdasarkan dari Petunjuk Teknis Standar Pelayanan Kefarmasian di Rumah Sakit Tahun 2019 [7]. Berikut merupakan hasil perhitungan data frekuensi yang telah dilakukan 
Tabel I. Hasil Data Frekuensi Perencanaan Kebutuhan Obat Dan Pengadaan Obat Di Rumah Sakit Mitra Siaga Kabupaten Tegal

\begin{tabular}{llc}
\hline \multicolumn{1}{c}{ Kegiatan } & \multicolumn{2}{c}{ Kesesuaian } \\
& Sesuai & Tidak \\
\hline $\begin{array}{l}\text { Perancanaan } \\
\text { kebutuhan }\end{array}$ & $100 \%$ & $0 \%$ \\
Pengadaan & $90,5 \%$ & $9,5 \%$ \\
\hline
\end{tabular}

\subsection{Perencanaan Kebutuhan}

Dari hasil penelitian diperoleh data frekuensi dari variabel pemilihan yang sudah didapatkan dari 42 responden.

\begin{tabular}{|c|c|c|}
\hline \multicolumn{3}{|c|}{ Kabupaten Tegal Tahun 2021} \\
\hline Baik $(80 \%)$ & 0 & 0 \\
\hline $\begin{array}{c}\text { Sangat Baik } \\
(100 \%)\end{array}$ & 11 & $100 \%$ \\
\hline Jumlah & 11 & 100 \\
\hline
\end{tabular}

(Data diolah, Mei 2021)

Dilihat dari tabel frekuensi data yang diperoleh dari kuisioner proses perencanaan kebutuhan obat dari 11 responden menunjukkan bahwasanya proses perencanaan kebutuhan obat sangat baik dengan perolehan nilai $100 \%$.

Petunjuk Teknis Standar Pelayanan Kefarmasian Di Rumah Sakit Tahun 2019 [7] menyatakan bahwa proses perencanaan obat yang baik yaitu apabila terdapat kendala kehabisan stok obat apoteker memberikan informasi kepada staf medik terkait kendala yang sedang terjadi untuk mendapatkan solusi substitusinya. Terdapat aturan petunjuk perencanaan kebutuhan juga harus memikirkan yang pertama tahapan dalam proses perencanaan kebutuhan obat d rumah sakit, proses menyampaikan RKO ke layanan E-Monev Obat dan memerhitungkan RKO dengan cara konsumsi, mordibitas, proxy consumption, Evaluasi perencanaan dan dengan metode revisi daftar obat.

Adapun data primer yang sudah didapatkan melalui wawancara terkait siapa saja yang melakukan proses perencanaan kebutuhan obat dengan kepala instalasi farmasi rumah sakit guna untuk lebih memperjelas atau mempertegas lagi data yang sudah didapatkan melalui data sekunder. Dari hasil wawancara dengan informan A, 38 Tahun mengatakan bahwa "Untuk proses perencanaan sendiri dilakukan oleh tim SPF logistik farmasi lalu diajukan lagi ke manager farmasi yang sudah dibuatkan RAB (Rancangan Anggaran Biaya) dalam hitungan satu tahun"

"Dan untuk proses perencanaan sendiri yang jelas kita lihat stok akhir dulu. Kemudian pola penyakit yang lagi tren di kalangan masyarakat dan di rumah sakit apa aja kemudian kita lihat stok akhinya dulu karena kita kan perencanaan dilakukan pada tiap bulan" tambah (A, 38 Tahun)

Sesuai dengan juknis rumah sakit tahun 2019 bahwa tahapan untuk proses perencanaan kebutuhan obat dilihat dari segi persiapan salah satunya yaitu perlu dipastikan kembali program dan komoditas apa yang akan disusun perencanaan dan proses perencanaan mempertimbangkan waktu yang akan diperlukan untuk memperkirakan waktu pengadaan, safety stock dan lead time.

Dalam proses perencanaan kebutuhan obat di IFRS yang pertama dengan melakukan pemeriksaan sediaan yang ada ditempat penyimpanan dan dilakukan oleh petugas yang bertanggungjawab di rumah sakit tersebut, setelah itu memperkirakan perkiraan pengiriman dengan berapa banyak item yang dibutuhkan dimana petugas yang melakukan juga melibatkan dengan bagian IFRS dan apoteker akan menyimpan hasil catatan totalan. Kebutuhan 
perencanaan obat tidak dilakukan untuk semua item obat dengan melihat dari berapa jumlah jenis obat yang masih tersedia dan obat yang masih dalam jumlah stok yang cukup akan dilakukan perencanaan pemesanan selanjutnya [8]

\subsection{Pengadaan Obat}

Dari hasil penelitian diperoleh data frekuensi dari variabel pemilihan yang sudah didapatkan dari 42 responden.

\begin{tabular}{|c|c|c|}
\hline \multirow{2}{*}{\multicolumn{3}{|c|}{$\begin{array}{c}\text { Kabupaten Tegal Tahun } 2021 \\
\text { Jumlah }\end{array}$}} \\
\hline & & \\
\hline Baik (80\%) & 1 & 9,5 \\
\hline $\begin{array}{l}\text { Sangat Baik } \\
\quad(100 \%)\end{array}$ & 10 & $90,5 \%$ \\
\hline Jumlah & 11 & 100 \\
\hline
\end{tabular}

Dilihat dari tabel frekuensi data yang diperoleh dari kuisioner proses perencanaan kebutuhan obat dari 10 responden menunjukkan bahwasanya proses perencanaan kebutuhan obat sangat baik dengan perolehan nilai $100 \%$. Adapun hasil lain yang menunjukkan $9,5 \%$ atau 1 responden yang menyatakan bahwa pengadaan obat belum berjalan dengan baik hal ini disebabkan karena belum bisa melakukan pengadaan obat dikarenakan pencairan dana BPJS yang telat karena sebagian besar dari pasien rumah sakit melakukan pembayaran dengan BPJS yang mengakibatkan pihak Rumah Sakit terlambat melakukan pembayaran dengan supplier yang menjadikan rumah sakit belum bisa memesan persediaan.

Adapun kendala yang terjadi pada proses pengadaan mendapat pernyataan dari informan yang mengatakan bahwa "Pengadaan banyak kendala yang berhubungan dengan pihak ketiga (supplier) belum bisa membayar karena belum melakukan pembayaran karena kan kebanyakan dari pasien kita itu pasien BPJS. Jadi ya kalau BPJS cairnya telat jadi pihak RS bayarnya telat. Jadi hubungannya tadi dengan obat yang kosong karena belum bayar" (A, 38 Tahun)

Adapun pernyataan lain dari informan A 38 tahun yang menambahkan bahwa "Proses pengadaan obat selain keterlambatan anggaran dari BPJS dan juga kalau kita pemesananya secara online. Kalau online kan kita harus menunggu" ujar (A, 38 Tahun)

Dari hasil wawancara dengan keempat kepala instalasi farmasi rumah sakit dapat disimpulkan bahwasannya pada proses pengadaan masih mengalami kendala seperti keterlambatan pemesanan obat yang mengakibatkan rumah sakit kekosongan stok obat di IFRS. Adapun cara lain kepala IFRS untuk menangani kekosongan obat yaitu dengan meminjam terlebih dahulu kepada rumah sakit lain obat yang sama dan yang dibutuhkan. Sudah ada kesepakatan antar kepala IFRS untuk saling membantu satu sama lain.

Penelitian oleh Gregorius [4] yang berjudul "Evaluasi Perencanaan Dan Pengadaan Obat Di Instalasi Farmasi RSUD Kefamenanu Kabupaten Timor Tengah Utara", menyatakan bahwa obat dengan kategori A sebanyak 48 item $(20,17 \%)$ dengan biaya pembelian sebesar $69,69 \%$, obat kategori B sebanyak 60 item $(25,21 \%)$ dengan biaya pembelian sebesar 20,14\% dan obat kategori $\mathrm{C}$ sebanyak 130 item $(54,62 \%)$ dengan biaya pembelian sebesar $10,17 \%$. Hal ini menunjukkan bahwa evaluasi terhadap perencanaan dan pengadaan obat untuk kelompok A di RSUD Kefamenanu belum berjalan dengan baik. Penelitian yang dilakukan adalah studi kasus dengan rancangan kasus tunggal holistik. 
Rumah Sakit harus memiliki mekanisme yang dapat digunakan untuk mencegah kekosongan stok obat yang secara normal tersedia di Rumah Sakit dan mendapatkan obat saat instalasi farmasi tertutup. Pengadaan dapat dilakukan melalui Pembelian dimana Rumah Sakit pemerintah dalam pembelian Sediaan Farmasi, Alat Kesehatan dan Bahan Medis Habis Pakai harus sesuai dengan ketentuan pengadaan barang dan jasa yang berlaku. Hal-hal yang perlu diperhatikan dalam pembelian adalah kriteria sediaan farmasi, alat kesehatan dan bahan medis habis pakai diantaranya kriteria umum dan kriteria mutu obat, persyaratan pemasok, penentuan waktu pengadaan dan pada kedatangan sediaan farmasi, alat kesehatan dan bahan medis habis pakai, pemantauan pada rencana pengadaan yang sesuai jenis, jumlah dan waktu, produksi Sediaan Farmasi. Instalasi Farmasi dapat memproduksi sediaan tertentu jika Sediaan Farmasi tidak ada di pasaran, Sediaan Farmasi lebih murah bila diproduksi sendiri, Sediaan Farmasi dengan formula khusus, Sediaan Farmasi dengan kemasan yang lebih kecil / repacking, Sediaan Farmasi untuk penelitian dan Sediaan Farmasi yang tidak stabil pada penyimpanan / harus dibuat baru (recenter paratus). Sediaan yang dibuat di Rumah Sakit harus memenuhi persyaratan mutu serta terbatas hanya untuk memenuhi kebutuhan pelayanan di Rumah Sakit tersebut. Yang kedua ada Sumbangan / Dropping / Hibah dimana Instalasi Farmasi harus melakukan pencatatan dan pelaporan khususnya penerimaan dan penggunaan sediaan farmasi, alat kesehatan dan bahan medis habis pakai sumbangan / dropping / hibah. Seluruh kegiatan penerimaan sediaan farmasi, alat kesehatan dan bahan medis habis pakai dengan cara sumbangan / dropping / hibah harus selalu disertai dokumen administrasi yang lengkap dan jelas. Agar penyediaan Sediaan Farmasi, Alat Kesehatan dan Bahan Medis Habis Pakai dapat membantu pelayanan kesehatan, maka jenis Sediaan Farmasi, Alat Kesehatan dan Bahan Medis Habis Pakai harus sesuai dengan kebutuhan pasien di Rumah Sakit. Instalasi Farmasi dapat memberikan rekomendasi kepada pimpinan Rumah Sakit untuk mengembalikan atau menolak sumbangan / dropping / hibah Sediaan Farmasi, Alat Kesehatan dan Bahan Medis Habis Pakai yang tidak bermanfaat untuk kepentingan pasien Rumah Sakit [7].

Pengadaan adalah proses kegiatan merealisasikan perencanaan kebutuhan. Pengadaan yang bagus juga harus melihat ketersediaan obat, jumlahnya, serta waktu yang pas dengan harga serta melihat peraturan kualitas. Adapun beberapa yang harus dilihat dari proses pengadaan ini adalah bahan baku obat wajib dengan sertifikat analisa, untuk bahan yang berbahaya wajib disertai Material Safeti Data Sheet (MSDS), wajib memiliki nomor izin edar dan periode kadaluarsa paling cepat dua tahun kecuali untuk persediaan yang tertentu yang dapat dipertanggung jawabkan. Rumah sakit juga wajib mempunyai cara kerja untuk menghindari kehabisan obat yang sudah umum ada di rumah sakit itu sendiri. Adapun prosedur pengadaan pembelian yaitu proses pembelian ini harus sama berdasarkan peraturan pengadaan, pembuatan Sediaan Farmasi. Sediaan yang diproduksi di rumah sakit wajib memenuhi persyaratan kualitas, pemberian atau sumbangan. Semua aktifitas penerimaan sediaan farmasi, alat kesehatan dan bahan medis habis pakai dengan sumbangan wajib dengan dokumen administrasi yang harus komplit supaya penyediaan dapat membantu pelayanan kesehatan [1]

\section{KESIMPULAN}

Hasil penelitian pelaksanaan standar pelayanan kefarmasian terkait dengan pengelolaan perencanaan kebutuhan dan pengadaan obat di rumah sakit Mitra Siaga Kabupaten Tegal dapat di simpulkan bahwa kesesuaian pelaksanaan kegiatan perencanaan obat $(100 \%)$ dengan kategori sangat baik dan pengadaan $(90,5 \%)$ baik sesuai dengan petunjuk teknis standar pelayanan kefarmasian di rumah sakit tahun 2019 


\section{DAFTAR PUSTAKA}

[1] Departemen Kesehatan Republik Indonesia, Peraturan Menteri Kesehatan Republik Indonesia No 72 Tahun 2016 Tentang Standar Pelayanan Kefarmasian di Rumah Sakit, 2016, Jakarta: Departemen Kesehatan Republik Indonesia

[2] Lolita, Penerapan Pelayanan Farmasi Klinis Di RSUD Ade Muhammad Djoen Kabupaten Sintang Tahun 2018 Berdasarkan Peraturan Menteri Kesehatan Republik Indonesia Nomor 72 Tahun 2016. Skripsi, 2019, Pontianak : Universitas Tanjung Pura.

[3] Anonimous, Standar Pelayanan Kefarmasian di Rumah Sakit. Standar Pelayanan Kefarmasian di Rumah Sakit Peraturan Menteri Kesehatan RI Nomor 58, 2014, Jakarta

[4] Gregorius, N., Evaluasi Perencanaan dan Pengadaan Obat di Instalasi Farmasi RSUD Kefamenanu Kabupaten Timor Tengah Utara. Jurnal Kebijakan Kesehatan Indonesia. Volume 07, pp. 147-153, 2018

[5] Jermias, S., Posangi, J., Joy, A. \& Ratu, M., Analisis Sistem Perencanaan Kebutuhan Obat di Instalasi Farmasi Rumah Sakit Umum Daerah Kabupaten Raja Ampat Provinsi Papua Barat. Papua Barat, 2017

[6] Meity, dkk, "Analisis Pengelolaan Obat Di Instalasi Rawat Inap Rumah Sakit Jantung Bina". Jurnal Manajemen dan Administrasi Rumah Sakit Indonesia. Volume 3 No 2, 2019

[7] Departemen Kesehatan Republik Indonesia, Petunjuk Teknis Standar Pelayanan Kefarmasian di Rumah Sakit Tahun 2019, 2019, Jakarta: Kementerian Kesehatan RI

[8] Mahdiyani, U dan Chairun, Evaluasi Pengelolaan Obat Tahan Perencanaan Dan Pengadaan di RSUD Muntilan Kabupaten Magelang Tahun 2015-2016, Jurnal Vol 8 No 1. 2018, Universitas Gadjah Mada Yogyakarta. 